\title{
Exploration of the Mineral World by X-Rays*
}

\author{
By Prof. W. L. Bragg, o.B.E., F.R.S.
}

$\mathrm{T}$ HE mineral world has supplied us with many of the most beautiful examples of crystal structure. Crystals grow best when the growth takes place in very constant conditions and very slowly, and these conditions are fulfilled in Nature in a way that cannot be rivalled in the laboratory. The beauty of natural crystalline forms has always attracted attention, and some of the rare and durable varieties have been prized, as jewel stones, as the most valuable of all natural objects.

The present is a suitable time to review our knowledge of the structure of the mineral world, because all the main types of minerals have been analysed. The existence of any well crystallised mineral has always been a challenge to those whose research is the analysis of crystals by $\mathrm{X}$-rays. Nature provides us with such excellent material on which to exercise our technique. The first crystals to be analysed were minerals, rock salt, diamond, fluor, blende, pyrites and calcite. For twenty years, the inquiry has been pursued, and with the recent analysis of the felspars it may be claimed that the main survey has been completed. There are, of course, many fascinating points of detail still to be investigated, but we can summarise the general laws which govern the different structures composing the solid crust of the earth.

We may first inquire how it is that we are able to speak of minerals as a limited class of chemical compounds. The number of compounds that can be formed from the chemical elements is endless. Yet the number of mineral species is restricted, and if we except the rare kinds which are found in odd corners where very special conditions have existed, the number is quite small. It must be admitted that part of the interest in mineralogy has been the interest of the collector. The fun of making a collection would be spoilt if Nature kept on producing endless new varieties of minerals.

The minerals are limited in number because they are the last survivors of the wear and tear of ages. They represent matter in the ultimate state of equilibrium. They have sunk into so deep a pit of low potential energy that no chemical change can tempt them to desert it.

This state of lowest potential energy is one of order and not of disorder. A crystal is more stable than a jumble of atoms. The perfect geometrical arrangement of a crystal represents matter in its most dead and inert form, from which nothing further in the way of change can be expected, just as the various Utopian schemes of society

* From an evening discourse to the British Association delivered at Aberdeen on Sept. 10. which have been put forward from time to time represent the most dull state in which it is possible to conceive living.

The world we are to study, then, is to be ruled by the laws of geometry. We will speak of tetrahedra, octahedra, angles, faces and edges. To appreciate this world, we must be like the Greek geometers, who were ravished by the beauty of the symmetrical solid figures. In no other science do these geometrical figures play so important a part; they are peculiar to crystallography. Though all crystals are based on geometrical patterns, the simplest regular geometrical forms are of outstanding importance in mineralogy just because minerals are so extremely inert. The condition for low potential energy imposes upon their configurations certain geometrical requirements, which are broken by the ephemeral compounds we prepare in the laboratory.

\section{Units of Mineral Pattern}

Eight elements compose 98 per cent of the earth's solid crust. In our broad survey, we will neglect all the other elements, most of which only occur in odd cracks here or there where we laboriously search for them. The common elements are oxygen, silicon, aluminium, iron, calcium, potassium, sodium and magnesium.

The bulk of the crust is oxygen. Not only is it the commonest element, but also it takes up the most room. The rocks are made of oxygen atoms cemented together by silicon, aluminium and a few other elements. According to the way in which they build up structures with oxygen, these elements are divided into three classes, to which we will have frequent occasion to refer.

(a) Elements forming the centre of a tetrahedral group. Four oxygen atoms are grouped together at the corners of a tetrahedron, and the element is situated at the centre. All the silicon is in this situation, and by far the greater part of the aluminium.

(b) Elements forming the centre of an octahedral group. Six oxygen atoms are grouped at the corners of an octahedron, with the element at the centre. This is the characteristic situation for magnesium and iron, and also for the remainder of the aluminium. Aluminium is peculiar in that it can play a double rôle, generally grouping itself with silicon, but sometimes behaving like the metals iron and magnesium.

(c) The bulky elements sodium, calcium and 
potassium. These elements are too large to be placed in tetrahedral or octahedral groups. They are accommodated in large, often unsymmetrical, holes in the structure.

The types of group are illustrated in Fig. 1. The tetrahedral and octahedral groups are the fundamental units of pattern-the stitches of which the mineral fabric is composed. All the common minerals, however complex their patterns, are a framework of these tetrahedral and octahedral groups. It must be realised that the groups are not distinct units, for there are not enough oxygens for each central atom to have its complete group belonging to it alone. The oxygen atoms of one group also form part of the next. It is very convenient to use the tetrahedra and octahedra in

FIG. 1. Association of common elements with oxygen in mineral structures. (Fig. 2a.)

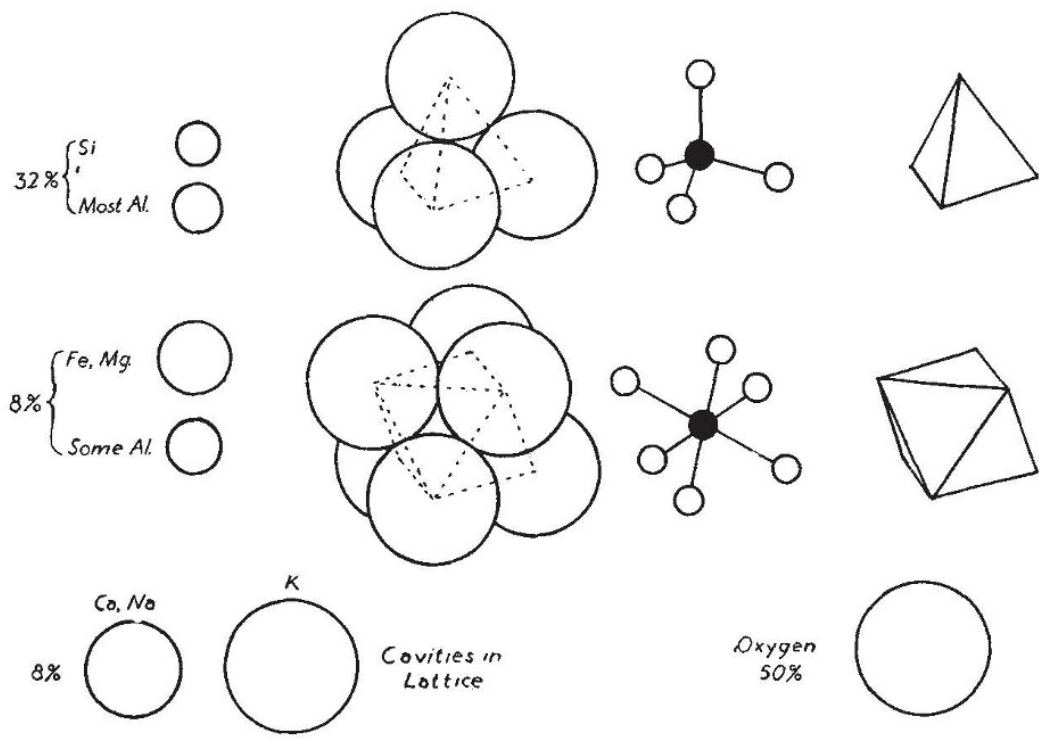

framework is the hardest part of the mineral, its skeleton, and it has the chief influence in deciding the form of the structure.

The most common minerals are quartz, felspar, mica, pyroxenes and amphiboles. The basic ferromagnesian silicates such as olivine may also be included. These great natural divisions of minerals have strikingly different physical characteristics, and are built up as follows:

(a) Olivine $(\mathrm{Mg}, \mathrm{Fe}) \mathrm{SiO}_{4}$. The $\mathrm{SiO}_{4}$ tetrahedra are not linked directly to each other, only by intermediate octahedral groups round $\mathbf{M g}$ or Fe.

(b) Pyroxenes and Amphiboles. $\mathrm{MgCa}\left(\mathrm{SiO}_{3}\right)_{2}$, $\mathrm{Mg}_{5} \mathrm{Ca}_{2}\left(\mathrm{Si}_{4} \mathrm{O}_{11}\right)_{2}(\mathrm{OH})_{2}$. The tetrahedral groups are linked into endless chains by stringing them together corner to corner. These chains are held together sideways by magnesium and iron octahedra. (Fig. 2b.)

(c) Micas. $\quad \mathrm{K}\left(\mathrm{Al}_{2}, \mathrm{Mg}_{3}\right)$ $\left(\mathrm{AlSi}_{3} \mathrm{O}_{10}\right)(\mathrm{OH})_{2}$. The tetrahedral groups, containing both $\mathrm{Si}$ and $\mathrm{Al}$, are linked into endless sheets. These sheets lie on each other like the leaves of a book; and are bound together in various ways. (Fig. 2c.)

(d) Felspars. $\mathrm{KAlSi}_{8} \mathrm{O}_{8}$, $\mathrm{NaAlSi}_{3} \mathrm{O}_{8}, \mathrm{CaAl}_{2} \mathrm{Si}_{2} \mathrm{O}_{8}$. The tetrahedra form a framework in three dimensions, each tetrahedron being linked by every corner to another. The framework has the composition (Al, Si) $\mathrm{O}_{2}$. The bulky ions $\mathrm{K}, \mathrm{Na}$, $\mathrm{Ca}$ are in open spaces within it. (Fig. 2d.)

(e) Quartz. $\mathrm{SiO}_{2}$. This is a structure composed entirely of tetrahedra containing $\mathrm{Si}$, linked everywhere corner to corner.

The type of structure corresponds to the composition of the mineral, in particular to the ratio of the first group of elements (those inside tetrahedra) to the available oxygen. For example, if there are four oxygens or more to every silicon, we have separate $\mathrm{SiO}_{4}$ groups. If there are only two oxygens to every silicon, the tetrahedra must share every corner in order that each Si may have four oxygens around it, and the structure of quartz is the result. The intermediate types of linking represent intermediate ratios :
(a) $\mathrm{SiO}_{4}$
(b) $\mathrm{SiO}_{3}$
Separate $\mathrm{SiO}_{4}$ groups
Olivine
$\mathrm{Si}_{4} \mathrm{O}_{11}$
Single chains
Pyroxenes
(c) $(\mathrm{Si}, \mathrm{Al})_{2} \mathrm{O}_{5}$
Double chains
(d) $\left(\mathrm{Si}, \mathrm{Al} \mathrm{O}_{\mathrm{s}}\right.$ Nets
(e) $\mathrm{SiO}_{2} \quad$ Networks

are stronger than the octahedral links, and very much stronger than the links of the bulky elements calcium, sodium and potassium. The tetrahedral 


\section{Properties and Structure}

We may now consider some properties conferred upon the minerals by these characteristic forms of grouping.

(a) Olivine.--In olivine the separate $\mathrm{SiO}_{4}$ tetrahedra are linked together by $\mathrm{Fe}$ and $\mathrm{Mg}$ octahedra. It is geometrically possible to do this in an extremely compact way, without wasting any space. The mineral is also very uniform in texture, since there are no exceptionally strong bonds in one direction rather than another. Hence we have a heavy compact mineral of a glassy texture.

(b) Pyroxenes and Amphiboles.-These are composed of strings of tetrahedra, linked side by side by the $\mathrm{Fe}$ and $\mathrm{Mg}$ octahedra. As is to be expected, they are all fibrous in nature, splitting very easily along the chains but not across them. Asbestos is a well-known example of such a mineral. Asbestos fibres are most remarkable. One can tie an overhand knot in a fibre and pull it tight without breaking it, just as one can with a cotton thread. Familiarity lessens our surprise, but it is really extraordinary that a knot can be tied in a stone with such ease. This property arises from the very strong bonds along the chains of tetrahedral groups, and the relatively weak links which bind the chains together laterally.

These minerals are divided into two great classes, the pyroxenes and amphiboles. They are distinguished by their cleavage. The cleavages cross each other at about $90^{\circ}$ in the pyroxenes, and $56^{\circ}$ in the amphiboles. The reason for this difference was discovered by Warren. All pyroxenes are based on single chains of tetrahedra, all amphiboles on double chains, two chains being linked side by side to form a kind of tape. When we look at the chains end on, it will be seen that the amphibole chains have a much more oblong cross-section. The consequence is that the cleavage cracks, in avoiding cutting the chains, cross each other more obliquely in the amphiboles.

(c) Mica.--Sheets of mica cleave with extreme ease. A sheet can be split again and again into thinner lamellæ in an apparently endless way.

The structure of mica was first analysed by Pauling. The main feature is a series of sheets of tetrahedra, each tetrahedron being linked by three corners to neighbours to form a hexagonal network. Two such sheets are then linked together by $\mathrm{Al}, \mathrm{Mg}$, or $\mathrm{Fe}$ octahedra to form a composite sheet. It is these double sheets which are so immensely strong, and enable mica to be cleaved so easily, because each is only fastened to its neighbours on either side by the weak attractions of potassium atoms lying between them.

The perfection of the mica cleavage is a truly remarkable phenomenon. It runs along the plane where the potassium atoms are situated, and may run for a centimetre or more without deviating from this plane by a single atom. We can show this, as Friedel first pointed out, by growing crystals of ammonium iodide, $\left(\mathrm{NH}_{4}\right) \mathrm{I}$, on the mica. The ammonium atoms in this salt happen to have precisely the same arrangement as the potassium
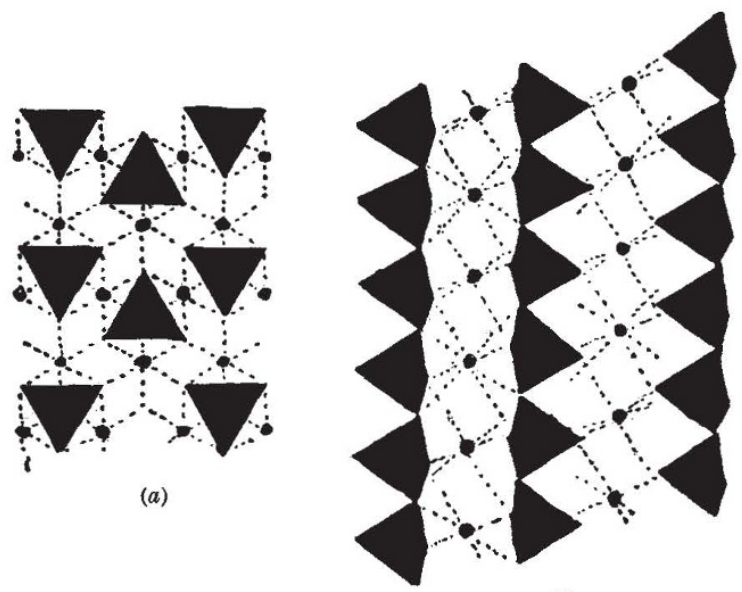

(b)
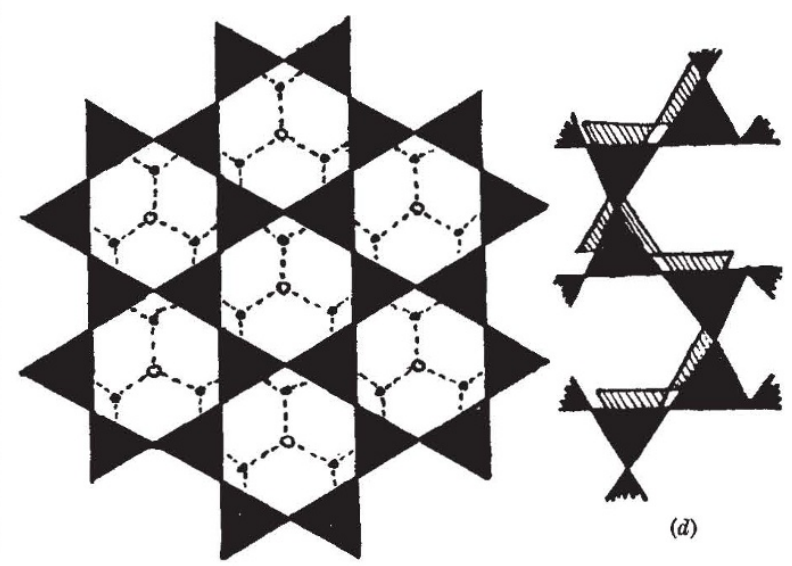

(d)

(c)

FIG. 2. The arrangement of the (Si, $\mathrm{Al}$ )-O tetrahedra in the common minerals. Tetrahedra are silhouetted in black. (a) Olivine, separate
groups ; (b) Pyroxene, chains; (c) Mica, sheets ; $(d)$ Felspar, three dimensional network.

atoms in mica, both in shape and scale. In consequence, the crystals all grow in parallel orientation on the mica. The grain of the pattern in successive molecular sheets of mica points alternately to right and left of its symmetry plane, hence the little crystals of ammonium iodide also point to right or to left depending on which type of sheet forms the top surface of the mica. If 
they all point the same way, the top sheet must be the same all over the surface. Fig. 3 shows a mica surface in two steps, all the crystals pointing one way on one side and in the reverse direction on the other.

The 'grain' is less marked in micas (biotite, phlogopite) with the formula $\mathrm{K}(\mathrm{Mg}, \mathrm{Fe})_{3}\left(\mathrm{AlSi}_{3} \mathrm{O}_{10}\right)$ $(\mathrm{OH})_{2}$, than in micas (muscovite) with the formula $\mathrm{KAl}_{2}\left(\mathrm{AlSi}_{3} \mathrm{O}_{10}\right)(\mathrm{OH})_{2}$; hence in the former case the ammonium iodide crystals point indifferently in either direction.

The mica-like sheets form the basis also of the clay minerals. These are single sheets of tetrahedra with an active side of vertices and an inactive side of bases. The clay minerals are little hexagonal spangles, a kind of mineral 'leaf-mould'

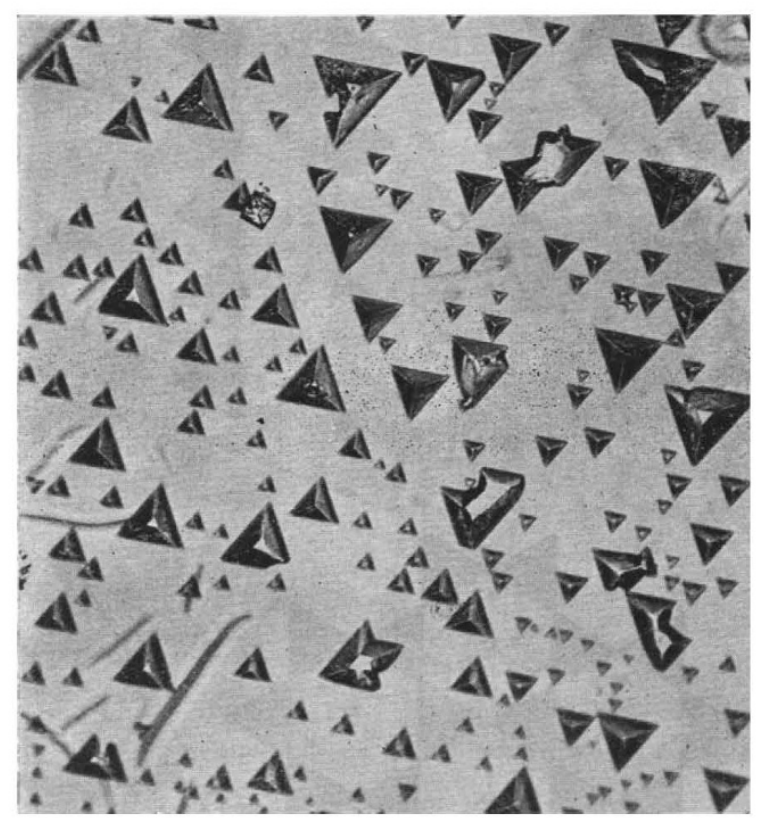

FIa. 3. The growth of ammonium iodide on mica (Iepidolite). A sub-microscopic step on the mica sheet separates the two areas where the ammonium iodide crystals point in opposite directions. Each area is a true plane to within a single molecule. ( $\times 80$.) Photograph by Mr. C. W. Bunn, Imperial Chemical Industries, Research

formed by the breakdown of other rocks. Their curious chemical and physical properties, so important to the soil, are the result of their platy character.

(d) Felspar.-This is the most important mineral of the earth's crust. We are familiar with it as a main constituent of granite. It is composed of $\mathrm{Si}$ and $\mathrm{Al}$ tetrahedra linked by every corner in every direction, a three-dimensioned latticework of tetrahedra. The bulky atoms $\mathrm{Na}, \mathrm{K}, \mathrm{Ca}$ are immeshed in its interstices.

We may only refer here to two of its interesting properties. In the first place, if we make a structure of tetrahedra linked by all their corners in this way, it is geometrically impossible to fit octa- hedra on to it. In consequence, magnesium and iron, which are characteristically in octahedral groups of oxygen atoms, are excluded from the felspar structures. We never find these metals in felspar.

In the second place, the felspars are divided into two great families. The more symmetrical orthoclase, $\mathrm{KAlSi}_{3} \mathrm{O}_{8}$, is typical of one family, and the less symmetrical albite and anorthite, $\mathrm{NaAlSi}_{3} \mathrm{O}_{8}$ and $\mathrm{CaAl}_{2} \mathrm{Si}_{2} \mathrm{O}_{8}$, of the other. The difference is simply a question of the size of the large cation. Potassium is so large that when inserted into the framework it holds it distended into the symmetrical form, whereas the smaller sodium or calcium allow it to sag over into a lop-sided unsymmetrical shape. This explanation is due to Taylor, who first analysed the felspars.

\section{Densimies of Minerals}

Finally, I wish to refer to another broad feature of minerals, their densities. The densities again depend to a large extent upon considerations of geometry. If we pack isolated tetrahedra together with octahedra, as in olivine, space can be utilised in a most economic way. It is geometrically possible to arrange the structure so that a maximum number of oxygen atoms, with their concomitant cations, are included in a given volume. On the other hand, building up a structure by attaching tetrahedra corner to corner is most wasteful as regards volume. It produces an expanded structure containing large open spaces.

In consequence we find that olivine is the heaviest, and felspar and quartz are the lightest, of the common minerals, others being intermediate. The greater the extent of the tetrahedral linking, the lighter the structure, as the following list shows:

\begin{tabular}{|c|c|c|c|}
\hline Olivine & & & $\begin{array}{l}\text { Density. } \\
3 \cdot 4\end{array}$ \\
\hline Pyroxene, & amphibole & & $3 \cdot 3-3 \cdot 1$ \\
\hline Mica & $e^{*} \quad$. & . & $2 \cdot 85$ \\
\hline Quartz & . & & $2 \cdot 65$ \\
\hline Felspar & . & & $2 \cdot 75-2 \cdot 55$ \\
\hline
\end{tabular}

The fact is, of course, that the earth's crust is mostly composed of these minerals, with felspar and quartz predominant, just because they are the lightest and so float to the top. According to the scale of densities, the light felspars float on the heavier ferro-magnesian silicates, and these in turn probably on metallic sulphides and metals which are much denser. Geometry is again triumphant. The fortunate existence of a raft of rock on which life is possible is seen to be a result of the geometrical properties of tetrahedra and octahedra. 